\title{
A identidade coletiva na União Europeia
}

Adam Holesch

\section{Resumo}

Após examinar algumas teorias sobre o nacionalismo, o autor afirma que só podemos falar de uma frágil identidade europeia. Seus principais argumentos são: primeiro, a União Europeia nem pode ser "inventada", nem pode depender da ancestralidade e memórias comuns compartilhadas; segundo, a União Europeia não dispõe de ferramentas suficientes para construir uma "nação".

Palavras-chave: União Europeia; Identidade Coletiva; Teorias do Nacionalismo; Ferramentas de Construção da Nacionalidade.

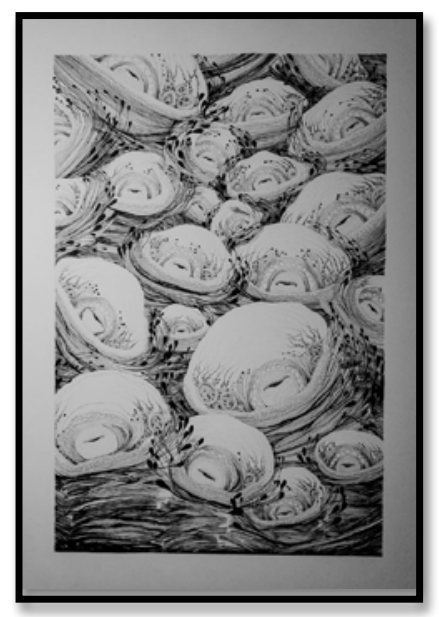

\section{Adam Holesch}

Pesquisador assistente na Universidade Pompeu Fabra, Barcelona.

\section{Collective identity in the European Union}

\section{Abstract}

After examining some theories on nationalism, the author claims that we can only speak of a fragile European identity. His main arguments are: first, the EU can neither been "invented" nor can it rely on shared memories and ancestry; second, the lacking nation-building tools of the European Union.

Keywords: European Union; Collective Identity; Theories of Nationalism; NationBuilding Tools. 


\section{INTRODUÇÃO}

Com a introdução do Tratado de Maastricht (1992-1993) iniciou-se um novo episódio no processo de integração europeia, que estacionou, temporariamente, em 2005, com o fracasso da Constituição Europeia. O processo de integração não apenas passou de um "consenso permissivo a um dissenso opressivo" (HOOGHEI; MARKS, 2009) como restabeleceu o problema de um "déficit democrático" (MARQUANT, 1979).

Conforme alega Bellamy (2006), a existência de um possível "déficit democrático" revela duas dimensões do problema, uma institucional e outra sociopsicológica. Enquanto a primeira tem a ver com a efetividade dos arranjos existentes na promoção da capacidade de resposta e na responsabilização dos líderes, a última diz respeito à questão de uma "amostra" europeia. É esta dimensão sociopsicológica que analisamos neste artigo.

Há uma grande diferença entre os antigos esforços de "construção nacional" e o atual processo de "construção identitária" europeu desenvolvido pela Comissão Europeia, especialmente depois da ratificação do Tratado de Maastricht. ${ }^{1}$ A discrepância torna-se visível tanto por conta da distância histórica quanto por causa do modelo constitucional da União Europeia (UE), que não guarda muitos aspectos de um Estado-nação. Depois que o Tratado de Lisboa entrou em vigor, em 2009, a UE poderia ser caracterizada como um sistema entre federação e confederação, ou como um sistema de múltiplos níveis de governança (HOOGHEI; MARKS, 2001). Além do mais, a UE não exerce monopólio sobre o uso legítimo da violência, um aspecto-chave na definição tradicional de Estado de Max Weber (1946). Em face da ausência de coerção, o processo de integração europeu não é nada mais que o primeiro experimento na "construção de uma identidade" coletiva em um sistema de governança de múltiplos níveis.

\footnotetext{
1 Há um problema de definição quanto a se a UE persegue construir uma "nação" ou uma "identidade". O fato é que a UE nunca reivindicou formar uma nação europeia e sempre empregou a expressão "construção de identidade", mesmo quando usa alguns instrumentos do passado típicos de construção das nacionalidades. Neste artigo o autor adota a expressão "construção de identidade".
} 
Como observado, a UE alega estar se posicionando para além do modelo de Estado-nação, desenvolvendo sua própria abordagem na construção de uma identidade europeia. Contudo, mesmo que ela tenha retomado o conceito de uma abordagem pós-nacional (HABERMAS, 1998), nunca ficou claramente definido como um conceito pós-nacional poderia ajudar a construir uma identidade europeia. Na verdade, consoante muitos pesquisadores, esta alegada nova abordagem tem sido construída em experiências anteriores de construção nacional dos membros da UE (SHORE, 2000; FOSTER, 1991). Com a introdução de uma moeda comum, o euro, parte da UE ganhou seu mais forte marco simbólico, porém, conforme dados empíricos, a moeda comum não conseguiu fortalecer uma identidade europeia comum - mesmo antes da crise europeia (EUROBAROMETER FLASH, 2010). Levando em conta estas considerações, esta análise levanta a seguinte questão de pesquisa: Que instrumentos a UE tem para resguardar uma identidade europeia?

Depois de explicar os problemas no tocante à definição de uma identidade europeia, esta análise irá examinar as principais teorias de nacionalismo, buscando sinais de como são formadas as nações e que ferramentas da "construção nacional" são vistas como cruciais neste processo. Estabelecido o quadro conceitual, analisaremos as ferramentas mais importantes da construção nacional dentro do esquema da "prática política" e também da "atividade simbólica" europeias (WALZER, 1967:194). Por fim, os resultados destas seções serão relacionados às perspectivas futuras de um processo de "construção identitária" europeia.

\section{IDENTIDADE EUROPEIA}

Segundo argumentam Brubaker e Cooper (2000), ao analisar as discussões acadêmicas sobre identidade, o conceito de identidade existente é não apenas irremediavelmente vago, mas também se firma em uma situação de anarquia por definição. Os autores adiantam sua própria definição, afirmando que identidades se conectam com a ideia de um grupo de pessoas reconhecerem uma semelhança fundamental que as leva a um sentimento de solidariedade entre si. Este sentimento é socialmente construído, 
inclusive a construção de um "outro", que significa o fato de eles serem diferentes. Ademais, como argumentam, a identidade jamais é completa ou totalmente estável.

$\mathrm{Na}$ análise da construção identitária europeia, uma definição correta é crucial. Tanto é difícil distinguir claramente uma identidade europeia de uma identidade nacional como o mero fato de usar o conceito de identidade europeia coletiva traz diversos riscos. Alguns estudiosos duvidam da existência de uma identidade europeia (SMITH, 1993; 1992); para outros ela existe, mesmo que somente como uma camada adicional (RISSE, 2010; FLIGSTEIN, 2008). A mensuração de uma identidade europeia também é problemática. Dados de pesquisas sobre a UE não definem que tipo de identidade está sendo mensurada, por exemplo, se trata de uma identidade étnica ou civil ou de um tipo de "associação cultural" (NAGEL, 1999).

Além disso, a força desta identidade é questionada. Assim, se alguém observa a primazia ou exclusividade da identidade europeia, dados do Eurobarometer indicam que apenas uma minoria insignificante se identifica como primária ou exclusivamente europeia. Contudo, se a identidade europeia é vista como compatível com a identidade nacional, mesmo que alguns se sintam mais nacionais que europeus, os dados da pesquisa podem ser interpretados como se a maioria tivesse uma identidade europeia (RISSE, 2010).

Neste prisma, a existência, mensuração ou vigor de uma identidade europeia é somente um dos problemas. Os outros são o conteúdo e as fronteiras que constituem tais identidades coletivas (BARTH, 1969). Ademais, quase não há dúvida de que poucos "morreriam pela Europa" (SMITH, 1995, p. 139), mas a identidade nem sempre é fervorosa e pode, às vezes, ser banal (BILLIG, 1995) ou expressa como uma "identidade não emocional" (GUIBERNAU, 2011). Todavia, seria isto suficiente para construir uma "amostra" europeia? Alguns pesquisadores veem o tipo de identidade disponível atualmente como base suficiente para a

2 Esta distinção remete a Kohn (1967 [1944]) e Meinecke (1970 [1907]), que opõem Staatsnation (nação estatal) a Kulturnation (nação cultural). 
política de legitimidade e redistribuição das instituições europeias (SCHMITTER, 2000; RISSE, 2010). Como este autor argumenta, a recente crise europeia (de 2008 em diante) mostra que, com vistas a melhorar o funcionamento da UE, é preciso muito mais do que apenas uma camada adicional de identidade. Porém, teria a UE os instrumentos para garantir uma identidade europeia coletiva tão forte e predominante?

\section{TEORIAS SOBRE NAÇÕES E NACIONALISMO NO CONTEXTO DA UNIÃO EUROPEIA}

Existem pelo menos três maneiras de enxergar a forma como nações 3 foram construídas: "modernismo", algumas vezes chamado "construtivismo"; "simbolismo-étnico"; e "perenialismo". ${ }^{4}$ As duas primeiras abordagens têm tido impacto particularmente forte uma na outra por meio de interatividade e de um constante aperfeiçoamento no estado-da-arte. Pesquisadores "modernistas" de nacionalismo, como Gellner (1983); Anderson (1983) e Hobsbawm e Ranger (1983), mudaram a forma de pensar sobre comunidades nacionais. Com o impacto das suas publicações, nações já não eram mais vistas como unidades naturais, contudo, mais uma vez, eram entendidas, no senso weberiano, como um fenômeno moderno. A despeito deste denominador comum, suas abordagens diferem de forma significativa. A interpretação de Gellner sobre nação e nacionalismo é fortemente sociológica, e acentuada pela transição de uma sociedade agrária para uma sociedade industrial, com todas as suas diferenças políticas e, sobretudo, culturais. Pesquisadores como Anderson se concentram na mídia e na imaginação, enquanto Hobsbawm e Ranger enfatizam a

3 A palavra "nação" deriva do vocábulo latino "natio" (nascer/nascido) e foi usada no Império Riomano para descrever de maneira negativa uma "comunidade de estrangeiros" (GREENFEL, 2001). Nas universidades medievais, a palavra "nação" era aplicada a comunidades de estudantes organizados em áreas geograficamente relacionadas, as quais eram definidas como nação. A questão de quando os conceitos de nação e povo se equipararam e de quando a palavra "nação" se tornou de uso comum tem sido debatida entre pesquisadores desde então.

4 Um dos perenialistas é Hastings (1997), que alega que etnicidade, nacionalismo e Estados-nação precedem o período moderno, o qual remonta ao século XI. 
"invenção da tradição". Além disto, outros acadêmicos têm desenvolvido importantes ideias, as quais nem sempre se transformaram em teorias. ${ }^{5}$

\subsection{Ernest Gellner e a modernização}

Para o antropólogo Ernest Gellner (1964), o nacionalismo é uma função da modernidade. Ele define nacionalismo da seguinte maneira: "O nacionalismo é, primeiramente, um princípio político, o que leva a entender que a unidade nacional e política deveria ser congruente" (GELLNER, 1983, p.1). Se grupos que são prejudicados durante o processo de industrialização não fossem culturalmente homogêneos com o grupo governante, eles poderiam pressionar para conseguir êxito. Assim, para Gellner, o nacionalismo se refere, acima de tudo, a conflito e separação de um Estado majoritário. Esclarecendo sua famosa frase: "É o nacionalismo que dá origem a nações e não o contrário" (1983[2006], p.54). Gellner enfatiza o fato de que nacionalistas não seguem um grande plano e de que suas ações são baseadas mais em coincidência do que em cálculo.

Para Gellner, duas pessoas são membros de uma mesma nação apenas se compartilham a mesma cultura e se reconhecem como pertencentes àquela entidade. Para desenvolver este tipo de pensamento, eles são culturalmente homogeneizados mediante alfabetização em uma linguagem vernacular expressa por uma educação de massa provida pelo Estado.

Em seu trabalho, Gellner não analisou a UE. Seu único caso de estudo foi um país hipotético chamado Ruritânia. Mesmo assim, muitas das suas ideias foram ressignificadas de uma análise de Estados multinacionais como o Império Otomano ou o Império Austro-Húngaro (Habsburgo). Por esta razão, de acordo com Gellner, a homogeneização cultural por meio da educação de massa está mais ligada à prevenção de uma secessão do que à construção de uma nova entidade, como no caso da UE.

5 Acadêmicos como Breuilly (1982) ou Tilly (1985) se concentraram nas implicações políticas do nacionalismo, mostrando que o Estado se transformou em um tipo de recipiente de poder, o qual, mediante interação dentro e fora do Estado, transformou seu povo em uma nação. 
Também a mobilidade industrial moderna, que mostra aos membros de uma cultura suas fronteiras culturais, é um aspecto importante da teoria de Gellner. Segundo o autor alega, a migração social e o emprego fizeram com que os camponeses apreciassem e amassem suas próprias formas de viver, porquanto tudo o que estava além das fronteiras conhecidas era "alienígena". Assim, Gellner enfatiza o impacto negativo da mobilidade, quando visto sob uma ótica "modernista". Ambos os aspectos do pensamento de Gellner, a influência da educação e a da mobilidade trabalhista, serão analisados no contexto da "construção de identidade" europeia.

\subsection{Benedict Anderson e as comunidades imaginadas}

A abordagem de Anderson em Comunidades imaginadas (1983) é outro forte conceito "modernista". Conforme afirma Anderson em sua teoria, os membros de uma nação não são capazes de encontrar-se uns aos outros pessoalmente e, por isso, sua coesão social tem de ser imaginada. A nação se tornou popular por conta da primazia do capitalismo e sua casual, porém explosiva, interação com as possibilidades oferecidas pela imprensa, e o fato de as pessoas geralmente falarem diferentes linguagens vernaculares. Depois da saturação do mercado de elite do latim, o capitalismo se expandiu para um mercado vernacular muito maior; reforçado pela nova ética do trabalho calvinista/protestante. Neste sentido, o latim dominante e as comunidades sagradas integradas por ele foram, gradualmente, fragmentadas e pluralizadas. Dentro do esquema do capitalismo editorial, novas esferas de comunicação, com diferentes línguas, se formaram, criando comunidades imaginadas, que leem os mesmos jornais, livros e revistas.

A "comunidade imaginada" não apenas enfatiza aspectos comuns, mas também faz com que conflitos do passado sejam esquecidos, um ponto significativo para Anderson, o qual ele toma emprestado do pensamento de Renan (1882). Neste contexto, Anderson atribui importância à história, explorada de maneiras particulares como a instituição das disciplinas de história nas universidades do começo do século XIX. Conforme ele pondera, 
a segunda geração de nacionalistas começou a falar em nome de pessoas mortas - levando ao esquecimento de "antigas tragédias", mas ressaltando o esforço feito no passado para que a nação se mantivesse unida.

Que pontos da teoria de Anderson poderiam ajudar a definir as ferramentas mais importantes da "construção da identidade" na UE? O aspecto do capitalismo editorial, que formou uma esfera de comunicação comum, é certamente um dos aspectos a serem analisados; também a forma de modelos de comunicação modernos, tal como a radiodifusão. No Nacionalismo Ocidental e Oriental, Anderson (1992) argumenta que a mídia eletrônica já exerce influência mais marcante do que a mídia impressa, a qual ele define como "mãe natural do nacionalismo". Ambos os tipos serão analisados.

\subsection{Hobsbawm e Ranger e a invenção da tradição}

De acordo com Hobsbawm e Ranger em seu histórico trabalho A invenção da tradição (1983), já que a transformação do Estado nos tempos modernos começou a destruir velhos modelos sociais, novas tradições tiveram de ser inventadas, de modo a fortalecer a coesão social, legitimar novas instituições e introduzir e socializar novas crenças, valores e normas. ${ }^{6}$ Como eles alegam, tradições inventadas são acumuladas em todas as sociedades e uma língua detalhada de práticas simbólicas e de comunicação está sempre disponível. As primeiras e mais poderosas tradições são o hino, a bandeira e a personificação da nação em símbolo ou imagem.

Para Hobsbawm e Ranger, as principais diferenças entre as antigas tradições "verdadeiras" e as "inventadas" são as seguintes: práticas "verdadeiras" eram exercícios sociais específicos e fortemente ligados, enquanto "tradições inventadas" estão associadas a questões de valores, direitos ou obrigações, tais como "patriotismo" ou "dever", expressos, por exemplo, no ato de levantar-se

6 Hobsbawm e Ranger (1983, p. 1) definem "tradições inventadas" como "um conjunto de práticas, normalmente governadas por regras abertas ou tacitamente aceitas de uma natureza ritual ou simbólica, a qual procura inserir determinados valores e normas de comportamento por meio da repetição; implicando automaticamente em uma continuidade com o passado" (1983, p. 9). 
quando se canta o hino; "tradições inventadas" preencheram apenas uma pequena parte do espaço deixado pelas velhas tradições, sobretudo na esfera privada; "tradições inventadas" desenvolveram um impacto muito maior na esfera pública em instituições como escolas, nos meios de comunicação de massa, nas forças armadas, na lei, ou na cidadania.

A abordagem de Hobsbawm e Ranger a respeito da "tradição inventada" é uma fonte rica para a análise da UE, que inventou muitas das suas novas tradições sem mencionar, obviamente, em inúmeros casos, que elas estão vinculadas ao passado. Na segunda parte deste estudo, analiso se as tradições inventadas ajudam a construir ou fortalecer uma identidade comum europeia.

\subsection{Anthony Smith e o mito comum}

Anthony D. Smith (2009) concorda com o pressuposto "modernista" segundo o qual nações são um fenômeno real e moderno, mas contradiz a visão "instrumentalista" de que nações são apenas uma particularidade ou um produto da modernidade, fortemente influenciado e manipulado por certas elites. Na argumentação de Smith, "nacionalismos políticos modernos não podem ser compreendidos sem referências a [estes] laços étnicos e memórias prévios e, em alguns casos, a comunidades e identidades étnicas pré-modernas" (SMITH, 1996, p.358). De acordo com Smith, estas origens étnicas das nações explicam por que o movimento nacionalista conseguiu mobilizar pessoas em apoio a seu projeto de construção nacional. Smith faz distinção entre identidade individual e identidade coletiva. A identidade individual é mais fraca, mais suscetível a mudanças, e nela o indivíduo pode experimentar diferentes identidades ao mesmo tempo; identidades coletivas, por sua vez, são fortes e persistentes, apesar de, algumas vezes, não serem sentidas tão fortemente por aqueles que as detêm.

Por conta do extenso número de publicações de Smith, é difícil distinguir claramente as ferramentas mais significativas de construção de uma identidade nacional, sobretudo porque os termos que ele usa sofreram variações durante mais de quatro décadas de publicações. Contudo, este autor decidiu se concentrar no esquema de Smith do complexo "mito-símbolo" como o estatuto fundador, 
o mito dos "anos dourados", e as memórias comuns ligadas ao próprio território (SMITH, 1986)..$^{7}$ Embora Smith tenha dado uma resposta clara sobre as possibilidades de uma identidade europeia, argumentando que "qualquer tentativa de 'criar fatos nacionais ou supranacionais' dificilmente será bem-sucedida nos níveis cultural e social" (1993, p.134), ele não analisou todos os instrumentos que considerava importantes em um processo de construção nacional. O presente artigo verificará se a análise de Smith do começo dos anos 1990 ainda seria válida duas décadas mais tarde.

\section{FERRAMENTAS DA “CONSTRUÇÃO IDENTITÁRIA" EUROPEIA}

\subsection{Educação e linguagem}

Como Gellner (1983) e Hobsbawm (1990) nos fazem recordar, a educação de massa é um dos principais instrumentos na composição de uma identidade nacional. A política educacional pode não apenas apoiar valores sociais, mas também fortalecer a mobilidade social. Ela também ajuda a manter uma estabilidade política (GREEN, 1997). Segundo alguns pesquisadores, o controle sobre a educação é essencial para o prospecto de legitimação das instituições europeias (OLSEN, 2002).

Ao mesmo tempo, a educação é um elemento altamente sensível em todos os processos de construção nacional. Isto leva à ansiedade em alguns Estados-membro da UE para os quais a homogeneização de sistemas educacionais implicaria a perda da sua identidade nacional (BUEKEL, 2001). Em consequência, governos são historicamente zelosos do seu monopólio sobre a política educacional. Também por esta razão, cada membro da UE tem poder de veto e a política educacional da entidade apenas pode refletir o mínimo denominador comum. Embora a UE possa ajudar no desenvolvimento de uma educação de qualidade nos Estadosmembro, tais medidas de incentivo têm de ser decididas por uma maioria qualificada no Conselho e em co-decisão com o Parlamento

7 Em outras publicações, Smith destacou as seguintes ferramentas de construção nacional: rituais e cerimônias, mitos e símbolos políticos, as artes e livros de história. 
Europeu (Art. 165-166 do Tratado sobre o Funcionamento da UE, anteriormente Art. 149 do Tratado que institui a Comunidade Europeia). Como acordado, os tratados europeus não permitem a harmonização do conteúdo dos sistemas educacionais dos Estados-membro.

Com a introdução do Tratado de Maastricht, a educação na UE deve se tornar um poderoso instrumento, de modo a estabelecer algo no sentido de uma identidade europeia. Questões de identidade e cidadania foram parcialmente discutidas mediante generosos financiamentos feitos pelo quinto programa estrutural da UE (1998-2002). Esta evolução chegou a um fim quando, por conta das tendências de globalização, a UE gradualmente se distanciou do seu objetivo político de criação de uma identidade europeia e foi em direção a objetivos mais econômicos em sua política educacional. Então, a "identidade europeia" foi lentamente substituída por conceitos como "recursos humanos" e "capital humano". Desde 1999, publicações da Comissão Europeia negligenciam o potencial da educação na criação de identidade e, ao invés disso, se concentram no valor econômico da educação (WALKENHORST, 2008).

O Processo de Bolonha ${ }^{8}$ é a mais clara manifestação dessa mudança de paradigma. Ministros da Educação de quase todos os países europeus instituíram o "Espaço Europeu de Ensino Superior" (EHES, na sigla em inglês), porém o Processo de Bolonha foi colocado fora da UE, com evidentes intenções econômicas. Isto deveria tornar o EHES mais compatível, comparável, competitivo e atrativo para estrangeiros de todo o mundo (COMISSÃO EUROPEIA, 2003a, p. 2). Contudo, mesmo que a Bolonha claramente se concentrasse em questões econômico-funcionais, muitos dos outros programas da UE ainda se baseiam na coordenação e cooperação, tal como intercâmbios, financiamento e informação.

O programa de intercâmbio bilateral ou multilateral mais popular entre universidades tem sido o Erasmus (sigla em inglês

8 Nota do Tradutor: Aqui, o autor se refere ao Processo de Bolonha, que estabeleceu um Espaço Europeu de Ensino Superior, e marcou uma mudança em relação às políticas de ensino superior na EU, reconhecendo a importância da educação para o desenvolvimento de sociedades democráticas. 
para Esquema de Ação Regional Europeia para a Mobilidade de Estudantes Universitários). Na perspectiva da Comissão Europeia, o programa ajudaria a desenvolver algo semelhante a uma identidade europeia (SHORE, 2000) e criar uma "geração Erasmus". Consoante confirmam publicações, sobre desenvolvimento do Erasmus, a adoção de um apoio para a UE foi, juntamente com considerações econômicas, central no projeto (SIGALAS, 2010). Uma avaliação dos resultados a curto prazo é inconclusiva. Enquanto Fligstein (2008) ou King e Ruiz-Gelices (2003) acreditam que a participação no Erasmus aumentou a identidade europeia dos estudantes e os fez mais conscientes e afeiçoados a outras culturas, para outros pesquisadores, como Sigalas (2010), o programa Erasmus fracassou em desenvolver uma autoidentidade europeia ou reforçar o orgulho dos estudantes europeus. Segundo argumenta Wilson (2011), a experiência do Erasmus não fez os estudantes mais pró-europeus por diversas razões. Em geral, cidadãos mais jovens da UE, e estudantes em particular, já se veem como mais europeus. Estudantes que participaram do Erasmus parecem particularmente pró-europeus, uma atitude que já adotavam antes do intercâmbio. Entretanto, existe um problema: todos estes estudos analisam somente os efeitos de curto prazo do Erasmus. Ainda não há estudos considerando os efeitos de longo prazo do programa. A nosso ver, uma linha de pesquisa dos efeitos de longo prazo mostraria um crescimento da identidade europeia.

Outro aspecto da abordagem de Gellner é que a educação de massa é oferecida em uma língua nacional, o que funciona, neste caso, como um tipo de "cimento social". Esta ideia foi amplamente rejeitada por Renan (1882). O pensador francês negou o laço linguístico como um importante elemento fundador da nação. De acordo com suas ideias, as línguas de um território podem mudar, e mais importante é a vontade do povo, levando em conta seus esforços anteriores e a atual escolha de viver junto, que une a nação.

Mesmo assim, muitas das nações tradicionais têm se concentrado no tópico da linguagem, um conceito desenvolvido por filósofos como Herder (1772) ou Fichte (1808). Consoante os dois pensadores alemães, no caso da UE, a linguagem, que geralmente 
é usada para fortalecer o "eu nacional", exerce o efeito absolutamente contrário.

Existem três idiomas principais na UE - o inglês, o francês e, até certo ponto, o alemão -, mas ela funciona, acima de tudo, em sua estrutura de 23 línguas oficiais e seis semioficiais. Oficialmente, a política de linguística da UE promove a multilinguagem e tenta encorajar seus cidadãos a falar pelo menos dois idiomas estrangeiros, além da sua língua pátria. Apesar de algumas iniciativas no setor educacional, em geral, a despeito destes esforços, uma grande parcela dos cidadãos europeus não pode se comunicar entre si. Diante desta realidade, existem algumas sugestões interessantes, tais como introduzir o inglês como uma segunda língua comum (HABERMAS, 2011) de modo a criar uma esfera pública europeia. Contudo, se houvesse uma obrigação ampla dos europeus terem habilidades em um inglês avançado, há dúvidas se a população abandonaria sua esfera pública nacional para se juntar a uma esfera pública europeia operando principalmente em uma língua estrangeira.

\subsection{Cidadania europeia e mobilidade}

No contexto europeu, a ideia de mobilidade, em geral, e de mobilidade espacial, em particular, tem de estar ligada a um conceito de cidadania europeia. Bauböck (2007, p.453) define a cidadania europeia como uma "associação encaixada em uma entidade política de múltiplos níveis que opera no nível dos Estados-membro e da União". Isto inclui duas características básicas: a representação democrática no nível supranacional, expressa por meio do direito dos cidadãos da UE de votar no Parlamento Europeu ou em eleições locais mesmo quando vivendo em um país estrangeiro; ou a liberdade de movimentação interna, ligada ao direito de morar ou trabalhar em todos os Estados-membro da UE (com algumas exceções temporais).

O problema mais evidente da cidadania europeia tem sido a liberdade de movimento dos cidadãos da UE, o qual começou com o Acordo de Schengen, em 1985, entre cinco dos dez Estadosmembro da Comunidade (Benelux, França e Alemanha). ${ }^{9}$ Além

9 NT: Benelux é uma união de países que compreende a Bélgica, os Países Baixos e Luxemburgo. 
do mais, o art. 45 do TFUE garante aos trabalhadores o direito de plena mobilidade. Na Europa, as taxas de mobilidade entre Estados-nação são baixas se comparadas às dos Estados Unidos; apenas 0,3\% da população se realoca, por ano, através das fronteiras dos seus países (HERM, 2008). De acordo com o EUROSTAT, em 2009, 31,9 milhões de cidadãos estrangeiros viviam em um dos 27 Estados-membro da UE, e 11,9 milhões deles eram cidadãos de outro Estado-membro da Comunidade.

Ao analisarmos a influência da mobilidade na identidade europeia, temos de levar em consideração duas maneiras diferentes de mobilidade. Primeiro, a já bem estudada parcela dos assim-chamados "Eurostars" (FAVELL, 2008), a elite altamente culta da Europa. Segundo, temos de analisar a mobilidade no sentido econômico clássico - na busca por emprego em outros países. Membros de ambos os grupos podem ser vistos como indivíduos ambiciosos que, historicamente, sempre deixaram seus países em busca de uma vida melhor: uma questão-chave da industrialização e formação do Estado-nação (WEBER, 1976).

Até agora, os "Eurostars" têm sido o objeto de análise mais frequente. Mesmo que em algumas publicações eles sejam considerados estatisticamente insignificantes, têm um alto valor simbólico para o projeto europeu e, geralmente, desenvolvem uma identidade europeia (FLIGSTEIN, 2008). Todavia, não há dados empíricos claros sobre o desenvolvimento da identidade europeia entre os europeus do centro-leste, uma população móvel que tem encontrado emprego na Grã-Bretanha desde a ampliação da UE para o leste.

Se os efeitos da mobilidade em massa ainda são inexplorados, o que dizer da própria cidadania da UE? Quando o Tratado de Maastricht entrou em vigor em novembro de 1993, todo cidadão de um país-membro da UE tornou-se automaticamente um "Cidadão da União" (Art. $8^{\circ}$ ). A questão mais destacada da cidadania na UE era "aumentar o senso de pertencimento da União e intensificar sua legitimidade" (COMISSION REPORT FOR THE REFLECTING GROUP, 2005, p.19-20).

Contudo, o significado do termo "Cidadão da União" é questionado. Como se pode definir alguém como "cidadão" ou como 
"membro de um Estado" se a UE não é um Estado no sentido convencional? Uma dificuldade adicional da UE tem sido o fato de que seus cidadãos não internalizam os direitos e normas da cidadania europeia, e não os conectam à cidadania europeia. Ao invés disso, eles se concentram em sua cidadania nacional. Esta situação se vincula a outros problemas da cidadania europeia: a maioria dos "novos" direitos estabelecidos no Art. $8^{\circ}$ do Tratado de Maastricht ou já existiam ou são tão limitados que não têm impacto legal.

Mesmo que os direitos de cidadania da UE sejam claros, quais seus deveres? O Art. $8^{\circ}$ não estabelece nenhuma obrigação. Além do mais, o conceito de cidadania está subordinado à estrutura do Estado-nação. A decisão final de quem é ou não um cidadão europeu cabe ao Estado-nação. Também não existe nenhum passaporte europeu neutro. Em suma, só é possível ser um cidadão da UE se for um cidadão de um Estado-membro da mesma.

Consequentemente, o papel da cidadania europeia desafia o princípio hegemônico de soberania nacional existente na Europa. O valor da cidadania europeia é, acima de tudo, simbólico, também relacionado ao Espaço Schengen. ${ }^{10}$ Isto se expressa, por exemplo, quando cidadãos da UE passam sem nenhum tipo de controle pela alfândega em aeroportos europeus. Portanto, a existência dos assim-chamados "Eurostars" também tem um caráter altamente simbólico. Ambos aspectos simbólicos são, sem dúvida, ferramentas fracas de construção nacional da UE; porém, eles estão mais próximos do conceito de tradições inventadas de Hobsbawm e Ranger, criado para ser uma justificativa central de uma identidade europeia que substitua a cultura ou linguagem comum inenixstentes.

10 NT: O Espaço ou Área Schengen se trata de um conjunto de 26 países, também membros da EU, que aboliram passaportes nacionais e estabeleceram um passaporte comum entre seus membros. 


\subsection{Esfera comunicacional - Mídia}

Enquanto para Hegel a leitura de um jornal era o substituto de uma oração matinal, para Anderson (1983) isto representa uma cerimônia de massa, na qual o participante sabe que outros membros da sua comunidade imaginada cumprem a mesma cerimônia. A cerimônia em massa do jornal e as notícias da noite passada na televisão eram celebradas diariamente. Contudo, os canais de notícias 24 horas, bem como a internet, permitem atualmente uma cerimônia permanente, que tem sido frequentemente customizada em um contexto nacional. Mediante esta permanência, a esfera da comunicação também se tornou, nos últimos anos, uma parte do nacionalismo "banal", operando por meio da sua repetição permanente de maneira bem inconsciente (BILLIG, 1995).

A questão da mídia europeia é fortemente relacionada à questão de uma esfera pública e de uma linguagem comum. Como argumentam alguns pesquisadores, sem uma linguagem comum, uma esfera pública comum não pode existir (GRIMM, 1995). ${ }^{11}$ Conforme outros estudos, ela existe sim, mesmo que a esfera pública europeia seja bastante pequena (DIÉZ-MEDRANO, 2009). Ainda que houvesse uma esfera pública comum, não há, a não ser por algumas exceções, uma mídia europeia comum. ${ }^{12}$ Mesmo que a Comissão Europeia tenha estado a par da informação - "Informação é um fator decisivo, talvez o mais decisivo, na unificação europeia..." (CEC, 1984, p.2) - muitas das suas iniciativas para estabelecer novas instituições midiáticas fracassaram ou permaneceram em uma fase embrionária (SHORE, 2000).

Um problema adicional não é apenas a UE não ter sua própria mídia. Simultaneamente, também existe a mídia nacional, que protege o Estado nacional e questiona todo movimento de

\footnotetext{
11 John Stuart Mill já chamou atenção para este problema em outro contexto: "Entre um povo sem sentimento de parceria, especialmente se eles leem e falam diferentes idiomas, a opinião pública unida, necessária ao funcionamento de um governo representativo, não pode existir" (MILL, 1861, p. 428).

12 A exceção são os canais de notícias europeus "Euronews" ou alguns jornais direcionados a Bruxelas, tais como o EU Observer, cuja distribuição é restrita a cidades onde haja instituições da UE.
} 
construção de uma identidade europeia. Há diferentes narrativas nacionais sobre a integração europeia. Em geral, o apoio à integração da UE segue este padrão: se a opinião dos cidadãos sobre a performance de instituições supranacionais é melhor do que a das instituições nacionais, então, seu suporte à integração da UE é maior (SÁNCHEZ-CUENCA, 2000). Os Estados-membro mais fortes da UE, tais como a Alemanha, a França e o Reino Unido, cujos cidadãos consideram que as instituições estão funcionando bem, têm uma mídia nacional crítica. Sabendo das preferências da esfera pública, a mídia geralmente lhes oferece uma narrativa "eurocética".

Ademais, projetos passados de construção nacional geralmente têm sido controlados pela esfera pública nacional; logo, têm estado fora do controle da comunidade internacional. Somente quando algumas posições extremas foram tomadas, a mídia e o público internacionais se interessaram. Atualmente, entretanto, múltiplos atores, tais como a mídia eurocética de diferentes países, governos nacionais, e atores internacionais como os Estados Unidos, monitoram o processo de construção da identidade europeia. Em suma, como no caso da lingua, a mídia é bastante contraproducente na construção desta identidade.

\subsection{Tradições inventadas / Simbolismo}

Junto com o conceito de "tradições inventadas", Hobsbawm vê os símbolos políticos como sucessores de "ícones sagrados" que foram largamente utilizados em práticas religiosas coletivas (HOBSBAWM, 1990, p.71). Hobsbawm conecta símbolos políticos a seu papel no processo de "engenharia social, o qual se insere na construção de nações" (IBID, p.10). ${ }^{13}$

13 O entendimento mais comum do papel dos símbolos é como "emblemas da vida em grupo", os quais "agem primariamente como instrumentos de comunicação" (KLATCH, 1988, p.139). Esta interpretação é bastante similar à abordagem de Emile Durkheim sobre "representações coletivas" (DURKHEIM, 1915 , p. 232) como um "sistema de símbolos através dos quais a sociedade torna-se consciente de si mesma" (IDEM, 1951, p.312). Pierre Bourdieu (1991), por sua vez, entende os símbolos como instrumentos de dominação. 
Na ótica de alguns pesquisadores, símbolos europeus são ferramentas provavelmente importantes na "construção da identidade" da UE, desenvolvidas e conscientemente utilizadas pelas elites europeias para proteger a legitimidade política e institucional da UE (SHORE, 2000; BRUTER, 2005). No entanto, como revelaram os bem-sucedidos protestos acerca da introdução de símbolos da UE na "Constituição Europeia", não apenas símbolos são considerados problemáticos por alguns membros da Comunidade, mas também este destaque dado a eles não é tão importante, porquanto são facilmente renegados por todas as partes envolvidas.

Em adição, o mais novo símbolo europeu, o euro, não apenas divide a UE em área do euro e área sem euro, como também quase não tem impacto sobre a identidade europeia da maioria dos cidadãos da área da moeda comum. E este é apenas um dos problemas do euro, que foi celebrado freneticamente como um marco simbólico de grande relevância. Uma comparação entre os países da área do euro e os que não estão nela mostra que cidadãos dos países do euro veem a moeda comum (49\%) como mais importante do que a liberdade de movimento (43\%). Por sua vez, países de fora da área do euro o mencionam apenas metade das vezes (23\%) em comparação à liberdade de movimento (47\%) (EUROBAROMETER, 2010, p.73).

Além do mais, consoante revela outro dado do Eurobarometer (EUROBAROMETER FLASH, 2010, p.306), o impacto do euro nos cidadãos da Europa tem efeitos bem ambivalentes. Em virtude de os números variarem em diferentes países europeus, pode-se afirmar que $67 \%$ dos cidadãos na zona do euro apoiavam decisivamente a moeda, mas para $77 \%$ destes mesmos cidadãos a moeda comum não tem absolutamente nenhum efeito nos seus sentimentos de ser europeu. ${ }^{14}$ Parece que o marco mais forte da UE é amplamente aceito em sua função econômica, porém, não consegue fortalecer a amostra comum europeia como um símbolo nacional.

14 Os $20 \%$ dos cidadãos que deram resposta positiva não serão analisados mais a fundo, particularmente devido ao "efeito seletivo", que significa que eles já poderiam se sentir "europeus", antes da introdução do euro. 
Outro símbolo fortemente reconhecido pelos cidadãos da UE, sua bandeira, não divide seus cidadãos, mas encontra problema em relação à exclusividade. Em geral, a bandeira tem sido sempre exibida lado a lado com a bandeira nacional em Estados-membro favoráveis à integração europeia. Portanto, uma bandeira europeia quase nunca é hasteada sozinha no contexto de um Estadomembro. Bandeiras são, geralmente, a expressão do "nacionalismo banal" em nações convencionais, com sua permanente exibição ou recordação de nacionalidade (BILLIG, 1995). O "nacionalismo banal", que funciona bem em âmbito nacional, é bastante problemático quando praticado em âmbito europeu, porque, para ser forte, ele deveria ser exclusivo. Quando hasteada juntamente com a bandeira nacional, a bandeira europeia é apenas uma lembrança banal de que a UE é um "Estado de Estados" e não um "Estado de pessoas".

E, ainda, o hino da UE, a "Ode à Alegria" de Beethoven, é reconhecido por apenas 36\% dos cidadãos da UE (EUROBAROMETER, 2005, p.62). Além disso, trata-se de um hino sem palavras; logo, não pode ser cantado. Raramente usado no contexto nacional, quando o é, costuma ser tocado antes ou depois do hino nacional. "Unidos na Diversidade", lema da UE, e o "Dia da Europa" também não são realmente conhecidos pelos seus cidadãos. Da mesma forma, o passaporte europeu, os sinais de fronteira, as habilitações para dirigir e as carteiras de identidade da UE são usados juntamente com os documentos nacionais e, por esta razão, não são muito efetivos (EUROBAROMETER, 2005, p.62).

\subsection{Mito comum da UE}

O pensamento central de Smith é a questão do mito. Esta ideia, desenvolvida por Malinowski (1926), retrata o mito como um quadro para legitimação. No caso da UE, o mito da fundação e o mito dos "anos dourados" são fortemente relatados. O mito da fundação pode ser relacionado tanto ao Tratado de Roma, de 1957, quanto ao calcanhar-de-Aquiles do discurso político popular e formal da nação europeia; dentre estes podemos contar a paz depois da Segunda Guerra Mundial ou os sucessos da integração 
europeia, tais como a integração econômica ou a ampliação para o leste da UE.

Sem dúvida, a Europa como um continente poderia encontrar seu mito nos "anos dourados", nos tempos do predomínio europeu, entre 1500 e 1918, mas é difícil converter este período em um mito positivo, por causa das permanentes e extensivas guerras intereuropeias da Era Colonial. Assim, a "história de sucesso" da integração europeia é forçada a representar os "anos dourados" da Europa, os quais ainda estão em construção. Contudo, ao mesmo tempo, consoante mostra um dado do Eurobarometer, a importância da paz e da prosperidade depois da Segunda Guerra Mundial vem perdendo sentido para os cidadãos da UE. Logo, este mito já está perdendo parte do seu possível impacto, mesmo antes de se desenvolver completamente.

Dificilmente, a memória coletiva europeia pode unir todas as nações europeias. Ela certamente divide, não unifica os europeus. Houve algumas tentativas por partes francófonas da Comissão Europeia de estabelecer algo como um mito comum europeu através de uma reescrita da história (SHORE, 2000; NAGEL, 1999). Estas tentativas, porém, fracassaram ante a impossibilidade de encontrar uma narrativa europeia comum.

Os arquitetos europeus também tentaram acentuar a unidade cultural baseada em uma civilização antiga comum. Esta abordagem é muito próxima daquela de "família de culturas", proposta por Smith, a qual poderia funcionar em longo prazo. A lei romana, a democracia política, instituições parlamentares, a ética judaico-cristã e a herança cultural como o humanismo renascentista, o racionalismo, o empirismo, o romantismo e o classicismo poderiam ser vistas como partes de uma cultura europeia. Mas como distinguir estes "valores europeus" de valores existentes, por exemplo, nos Estados Unidos? Até o momento, a UE tem sido incapaz de responder a esta questão.

Além do mais, o propósito social da UE, o mito do futuro, sugerido por alguns pesquisadores (HOWE, 1995; LEICESTER, 1996) para substituir memórias comuns não mais presentes, não pode realmente ajudar na construção de uma identidade coletiva. Ainda 
não ficou demonstrado que um símbolo representando o futuro pode ser realmente efetivo.

\section{CONCLUSÕES}

Este artigo tentou responder à seguinte questão: Que instrumentos a UE tem para garantir uma identidade europeia? Com base nas ferramentas de construção nacional encontradas nas mais importantes teorias sobre o nacionalismo, este estudo chegou aos resultados apresentados a seguir.

No setor da educação, a UE não possui muitas ferramentas. O programa de intercâmbio Erasmus apresenta resultados ambíguos, o Processo de Bolonha busca atingir objetivos econômicos e a reescrita dos livros de história é impossível. Ademais, a ferramenta da linguagem tem sido contraproducente, sendo um dos principais obstáculos para uma esfera pública comum. E, ainda, a ferramenta da mobilidade e a cidadania da UE são altamente simbólicas; a primeira é dominada por questões econômicas e a segunda se concentra nos princípios do Estado nacional. Não existe uma mídia europeia e a visibilidade de questões europeias na mídia nacional não melhora as atitudes em relação à UE; a mídia nacional, em geral, apresenta uma narrativa negativa sobre a UE. Considerando-se os símbolos europeus, a UE tem de dividir seus poucos elementos de construção de identidade com o Estado nacional; e ferramentas exclusivas da construção nacional, a exemplo da moeda, não apenas têm mais impacto simbólico econômico como também criam novos abismos, como no caso da divisão da UE em países da zona do euro e países que não fazem parte deste grupo.

Um instrumento usado persistentemente é o mito da fundação, ou o mito dos "anos dourados". Este instrumento, no entanto, ao invés de se fortalecer, tem se enfraquecido. Outros mitos não estão disponíveis e também não existem memórias europeias comuns de sucesso. Conforme mostram tais resultados, mesmo que identidades sejam dinâmicas e possam mudar rapidamente, devido a algumas conjunturas econômicas críticas ou eventos externos no futuro próximo, a construção de uma identidade comum europeia permanece uma tarefa complicada. Ainda que a dinâmica da 
construção da identidade compreendesse a visão de que a identidade europeia precisa de tempo para se desenvolver, o ambiente constantemente mutante desta identidade (fronteiras, a dinâmica da integração, como a zona do euro), torna cada um destes esforços de formação da identidade difícil ou até impossível.

Tradução: Camila Alves da Costa

\section{REFERÊNCIAS}

ANDERSON, B. Imagined Communities: Reflections on the Origin and Spread of Nationalism. Rev. ed. London. New York: Verso, 2006.

ANDERSON, B. Long-Distance Nationalism: World Capitalism and the Rise of Identity Politics. The Wertheim Lecture 1992. Amsterdam: Centre for Asian Studies, 1992.

BARTH, F. (ed.) Ethnic Groups and Boundaries. The Social Organization of Culture Difference. Bergen- Oslo: Universitets Forlaget, 1969.

BAUBÜCK, R. Why European Citizenship? Normative Approaches to Supranational Union. Theoretical Inquiries in Law. vol. 8, n. 2. p. 452-488, July 2007.

BELLAMY, R. Which constitution for what kind of Europe? Three models of European constitutionalism. In: F. CHENEVAL (ed.) Legitimationsgrundlagen der Europäischen Union, Berlin: LIT, p. 117-132, 2006.

BEUKEL, E. Educational policy institutionalization and multi-level governance, In: Anderson S. and K. Eliassen (ed), Making Policy in Europe, London: Sage. 2001. p. $124-39$.

BILLIG, M. Banal Nationalism. London: Sage, 1995.

BOURDIEU, P. Language and Symbolic Power. Cambridge: Harvard University Press, 1991.

BREUILLY, J. Nationalism and the State. Manchester: Manchester University Press, 1982.

BRUBAKER, R. and COOPER F. Beyond 'Identity. Theory and Society 29, [s.l.], 2000. p. 1-47. 
BRUTER, M. Citizens of Europe? : The Emergence of a Mass European Identity. Basingstoke ; New York: Palgrave Macmillan, 2005.

DÍEZ MEDRANO, J. The Public sphere and the European Union's Political Identity. In: European Identity, edited by Jeffrey T. Checkel and Peter J. Katzenstein. Cambridge: Cambridge University Press, 2009. p. 81-107.

EUROBAROMETER: 73, August 2010.

EUROBAROMETER FLASH: 306, September 2010.

EUROBAROMETER: 65, February 2006.

EUROBAROMETER: 62, August 2004.

FAVELL, A. Eurostars and Eurocities: Free Movement and Mobility in an Integrating Europe. Malden, MA: Blackwell, 2008.

FICHTE J.G. Reden an die deutsche Nation. In: Philosophische Bibliothek. Bd. 204, 5. Aufl., Hamburg: Meiner, 1978 [1808].

FLIGSTEIN, N. Euroclash: The EU, European Identity and the Future of Europe. Oxford: Oxford University Press, 2008.

FOSTER R. Making National Cultures in the Global Ecumen, Annual Review of Anthropology. [s.l.], 20, p. 235-260, 1991.

GELLNER, E. Nations and Nationalism. New Perspectives on the Past. Oxford: Blackwell, 1983.

GELLNER, E. Thought and Change. London: Weidenfell and Nicolson, 1964.

GREEN, A. Education, Globalization and the Nation State. Basingstoke: Macmillan, 1997.

GREENFELD, L. The Spirit of Capitalism: Nationalism and Economic Growth. Cambridge, Mass.: Harvard University Press, 2001.

GRIMM, D. Does Europe need a constitution? In: European Law Journal, vol. 1, n. 3, November 1995, reprinted. In: P. Gowan and P. Anderson (ed.). The Question of Europe, London 1997. p. 239-258, 1995.

GUIBERnAU, M. The Birth of a United Europe: On why the EU has generated a 'non emotional' Identity', Nations and Nationalism, vol.17 (2). p. 302-315, 2011. 
HABERMAS, J. Zur Verfassung Europas. Ein Essay. Suhrkamp, Berlin, 2011.

HABERMAS, J. Die Postnationale Konstellation: Politische Essays. Edition Suhrkamp. Frankfurt am Main: Suhrkamp, 1998.

HASTINGS, A. The Construction of Nationhood: Ethnicity, Religion and Nationalism. Cambridge: Cambridge University Press, 1997.

HERDER J.G. Treatise on the Origin of Language. In: Johann Gottfried von Herder: Philosophical Writings, ed. M. N. Forster Cambridge: Cambridge University Press, 2002.

HOBSBAWM, E. Nations and Nationalism since 1780. Cambridge: University Press, 1999.

HOBSBAWM, E. and T. RANGER. Introduction: Inventing Traditions. The Invention of Tradition. Cambridge: Cambridge University Press, 1983.

HOOGHE, L. and MARKS G. A Postfunctionalist Theory of European Integration: From Permissive Consensus to Constraining Dissensus. In: British Journal of Political Science 39. p. 1-23.

HOOGHE, L. and MARKS G. Multi-Level Governance and European Integration. Governance in Europe. Lanham, MD: Rowman \& Littlefield Publishers, 2001.

HOWE, P. A Community of Europeans: The Requisite Underpinnings. Journal of Common Market Studies, Vol. 33, n. 1, p. 27-46, 1995.

KING, R. and RUIZ-GELICES, E. International student migration and the European 'Year Abroad: effects on European identity and subsequent migration behaviour. Int. J. Popul. Geogr., V. 9, p. 229-252, 2003.

KOHN, H; The Idea of Nationalism. New York: Collier-Macmillan, 1967.

KRAUS, P. A Union of Diversity: Language, Identity and PolityBuilding in Europe. Themes in European Governance. New York: Cambridge University Press, 2008. 
MALINOWSKI, B. Myth in primitive psychology. London: Norton, 1926.

MARQUAND, D. Parliament for Europe. London: Jonathan Cape, 1979.

MEINECKE, F. Cosmopolitanism and the National State. Princetin. NJ: Princeton University Press, 1970.

MILL, J. S. Considerations on representative government. London: JM Dent, 1972.

NAGEL, K. J. Nation-building europea? Unificación europea i teories de la nació [s. n.], In: REQUEJO F. (Ed.): Pluralisme nacional i legitimitat democràtica. Barcelona: Proa, 1999. p. 187-205.

OLSEN J. The Many Faces of Europeanisation. In: Arena Working Papers. Oslo: [s. n.], 2002. p. 921-952.

PIETERSE, J. N. Fictions of Europe. Race and Class, 32 (3), p. 3 $-10,1991$.

RENAN, E. Qu'est-ce qu'une nation ? Paris: Imprimérie Nationale, 1996.

RISSE, T. A Community of Europeans? Transnational Identities and Public Spheres. Ithaca NY: Cornell University Press, 2010.

SÁNCHEZ-QUENCA, I. The Political Basis of Support for European Integration. In: European Union Politics, [s. 1.]: [s. n.]. vol. 1 (2), p. $147-171,2000$.

SCHMITTER, P. How to democratize the European Union -and why bother? Rowman \& Littlefield, Lanham, MD ; Oxford, 2000.

SHORE, C. Building Europe : The Cultural Politics of European Integration. London; New York: Routledge, 2000.

SMITH, A. D. Ethno-symbolism and Nationalism: A Cultural Approach. London: Routledge, 2009.

SMITH, A. D. Opening Statement: Nations and their pasts". In: Nations and Nationalism 2, [s. 1.], p.358-365, 1996.

SMITH, A. D. Nations and Nationalism in a Global Era. Cambridge: Polity Press, 1995. 
SMITH, A. D. A Europe of Nations. Or the Nation of Europe?. In: Journal of Peace Research, Vol. 30, n. 2, p. 129-135, 1993.

SMITH, A. D. National Identity and the Idea of European Unity. In: International Affairs 68.1, p. 55-76, 1992.

SMITH, A. D. The Ethnic Origins of Nations. Oxford: Blackwell, 1986.

SIGALAS, E. Cross-border Mobility and European Identity: The Effectiveness of IntergroupContact during the ERASMUS year abroad. European Union Politics.[S. i.] Vol. 11, n. 2, p. 241-265, 2010 .

WALKENHORST, H. Explaining change in EU education policy. Journal of European Public Policy. Vol. 15:4, p. 567-587, 2008.

WALZER, M. On the Role of Symbolism in Politic Thought. Political Science Quarterly 82, p. 191-205, 1967.

WEBER, E. J. Peasants into Frenchmen. Stanford: Stanford University Press, 1976.

WEBER, M. Selected Works. Oxford: Oxford University Press, 1946. 